\title{
Jejunum and Ileum Neuroendocrine Tumor pN1 TNM Finding v8
}

National Cancer Institute

\section{Source}

National Cancer Institute. Lejunum and Ileum Neuroendocrine Tumor pN1 TNM Finding v8. NCI Thesaurus. Code C135117.

Jejunum and ileum neuroendocrine tumor with regional lymph node metastasis in less than 12 nodes. (from AJCC 8th Ed.) 